\title{
A lateral pós-vocálica /1/ em comunidades baianas do Projeto Atlas Linguístico do Brasil (ALiB)
}

\author{
Robevaldo Correia dos Santos ${ }^{1}$ \\ Josane Moreira de Oliveira ${ }^{1}$
}

\section{Resumo}

Pautado nos pressupostos teórico-metodológicos da sociolinguística laboviana e da geolinguística pluridimensional, este artigo tem por objetivo investigar a realização variável da lateral pós-vocálica /l/ em posição de coda silábica em comunidades baianas do Projeto Atlas Linguístico do Brasil (Projeto ALiB). Para tanto, foram utilizadas na composição do corpus analisado 24 entrevistas com informantes naturais das seguintes localidades, integrantes da rede de pontos do Projeto ALiB: Euclides da Cunba, Barra, Jacobina, Seabra, Santo Amaro e Santa Cruz Cabrália. Os resultados apontam uma tendência à mudança, em que o apagamento da variável dependente tem sido abandonado pelos informantes mais jovens em favor da variante vocalizada, de modo que a implementação da vocalização apresenta estágios diferentes em cada uma das localidades selecionadas.

Palavras-chave: /l/ em coda silábica. Sociolinguistica. Geolinguística. Projeto ALiB

\footnotetext{
${ }^{1}$ Universidade Estadual de Feira de Santana.
} 


\section{Introdução}

Entende-se por uso variável de /1/ em posição de coda silábica as diferentes formas de realização dessa consoante em final de sílabas, como, por exemplo, em "balde", em posição interna de palavra, em que a consoante /l/ pode ser realizada como "ba[w]de", "ba[ł]de" ou "ba[h] de"; e em "capital”, em posição final de palavra, em que a vocalização [w], a velarização [1] e a aspiração [h] são possibilidades de realização da variável /1/, assim como também é possível o seu apagamento [Ø] (“capita[Ø]”).

Apesar da presença das variantes ([t], [h] e [Ø]), diferentes estudos (TEIXEIRA, 1988; BRANDÃO, 2008; CALLOU, 2009) indicam que a variante vocalizada ${ }^{3}$ [w] já se encontra estável na fala de muitas localidades. Embora haja vários estudos (HORA, 2006; LEITE, CALLOU, MORAES, 2007; PINHO, MARGOTTI, 2010; OLIVEIRA, COSTA, FARIA, 2013) a respeito da variação de /l/ em posição de coda no PB, considerando a grande dimensão geográfica do Brasil e a diversidade linguística do português, ainda há muito o que se fazer para dar a conhecer o comportamento dessa variável. Nesse sentido, justifica-se a investigação dessa variável no âmbito do território baiano, o que possibilitará conhecer melhor o comportamento do referido fenômeno em comunidades linguísticas desse espaço geográfico.

O corpus desta pesquisa é composto por 24 entrevistas com informantes naturais dos seguintes municípios baianos, integrantes da rede de pontos do Projeto Atlas Linguístico do Brasil ${ }^{4}$ (doravante Projeto ALiB): Euclides da Cunha, Barra, Jacobina, Seabra, Santo Amaro e Santa Cruz Cabrália. Em conformidade com a metodologia do Projeto ALiB, os informantes são estratificados pelos dois sexos, sendo quatro informantes em cada município, distribuídos por duas faixas etárias (faixa 1 - 18 a 30 anos e faixa $2-50$ a 65 anos), com escolaridade, no máximo, até o Ensino Médio.

Para visualizar a configuração linguística da variável /l/ no território baiano, assumindo o modelo teórico-metodológico da Sociolinguística variacionista e da Geolinguística pluridimensional, levantam-se as seguintes questões: a) ocorre variação de /l/ em posição de coda silábica na fala das comunidades analisadas? b) quais fatores

\footnotetext{
${ }^{2}$ Neste artigo, a variante aspirada será sempre representada por [h], tanto a sua realização surda quanto a sonora.

3 Por ser amplamente difundido na linguística brasileira, o termo "vocalização" é adotado ao longo do trabalho para fazer referência à semivogal $[\mathrm{w}]$.

${ }^{4}$ Disponível em: <http://www.alib.ufba.br/>.
} 
internos e/ou externos à língua podem ser associados ao fenômeno variável? c) trata-se de variação estável ou de mudança em progresso? Assim, as seguintes hipóteses são levantadas: o / / em posição de coda é variável na fala das comunidades investigadas, com a variante vocalizada $[w]$ já bastante disseminada na fala do interior baiano, mas não de maneira categórica; a variação de /1/ é condicionada por fatores linguísticos e sociais; a variação de /1/ aponta para uma mudança em progresso.

Inicialmente é feita uma revisão de alguns estudos sociolinguísticos do /1/ pósvocálico no PB, visitando alguns trabalhos que tratam do tema. Em seguida, mostram-se os procedimentos metodológicos, a composição do corpus, as localidades e o tratamento dos dados. Por fim, apresenta-se a análise dos dados e a discussão dos resultados.

Os resultados apontam uma tendência à mudança, em que o apagamento de /1/ tem sido abandonado pelos informantes mais jovens em favor da variante vocalizada, de modo que a implementação da vocalização apresenta, entre as localidades baianas selecionadas do Projeto ALiB, discretas diferenças percentuais, indicando diferentes estágios de mudança.

\section{Estudos sociolinguísticos do /1/ pós-vocálico no PB}

Pautando-se na perspectiva da sociolinguística laboviana, que pressupõe que os aspectos linguísticos e sociais estão imbricados e são uma condição sine qua non para a efetivação da mudança linguística, os trabalhos aqui visitados efetivaram a análise da correlação desses aspectos, demonstrando que a ocorrência de uma variante é favorecida tanto por grupos de fatores linguísticos como por grupos de fatores extralinguísticos, no sentido de que a alta frequência de uma variante está condicionada e não ocorre aleatoriamente, como propunham os estruturalistas, baseados na concepção de língua enquanto sistema de regras imune ao uso e às influências externas.

Para Labov (2008 [1972]):

não se pode entender o desenvolvimento de uma mudança linguística sem levar em conta a vida social da comunidade em que ela ocorre. Ou, dizendo de outro modo, as pressões sociais estão operando continuamente sobre a língua, não de algum ponto remoto do passado, mas como uma força social imanente agindo no presente vivo (LABOV, 2008 [1972], p. 21). 
Nesse sentido, as diferenças na estrutura social não podem ser desconsideradas nas análises dos processos de mudança linguística, sob pena de se anular qualquer possibilidade de interpretação coerente dos fatos linguísticos e obscurecer as explicações do funcionamento dos mecanismos de mudança. Acrescente-se ainda que "os princípios da geografia linguística combinados aos da sociolinguística podem ensejar um melhor conhecimento dos mecanismos com que opera uma língua e dos fatores que determinam sua evolução" (BRANDÃO, 1991, p. 12). A partir dessa perspectiva, a variação do segmento lateral pós-vocálico tem sido analisada em diversos estudos sobre o fenômeno em vários dialetos de diferentes regiões brasileiras.

Ao investigar a variação e a mudança linguística na fala dos habitantes do povoado de Saco Fundo, região de Monte Santo, na Bahia, a partir da análise de /1/ em coda silábica, Teixeira (1988, p. 40) diz que a vocalização dessa variável “em final de sílaba é um fato muito difundido na pronúncia do português do Brasil”; esse fenômeno, entretanto, não é uma exclusividade do / $/$, visto que o /r/ também tende a ser vocalizado nesse contexto, como, por exemplo, na palavra "terço/te[w]ço". A análise demonstrou que, em posição final de palavra, a vocalização $[\mathrm{w}]$ de /l/ é favorecida diante de [a] em contexto antecedente, sendo que o índice de favorecimento tende a diminuir à medida que a lateral

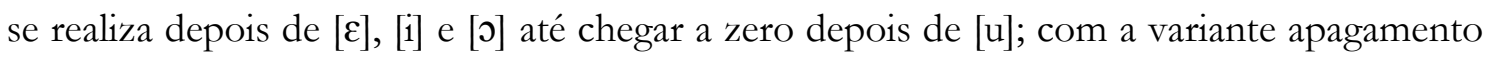
[Ø], ocorre o favorecimento no sentido inverso ao da vocalização. Quanto aos fatores externos, os dados de Teixeira (1988) revelam que os jovens têm a vocalização [w] como variante mais frequente e o apagamento [Ø] como segunda, enquanto o percentual de vocalização nos velhos é baixíssimo. Já o grupo de meia idade conserva a velarização [1] como variante mais frequente e a vocalização [w] como segunda.

A partir da análise de dados obtidos na cidade de João Pessoa, Hora (2006) constatou que a aspiração [h] da lateral ocorre no interior de vocábulo enquanto a variante [Ø] atua, principalmente, no final de vocábulo, considerando que, com menor frequência, o contexto de interior de palavra também favorece a ocorrência desta última. No que tange à faixa etária, os dados analisados por Hora (2006) revelam que os falantes de 15 a 25 anos e de 26 a 49 anos favorecem a variante vocalizada, com pesos relativos de 0,55 e 0,58, respectivamente, enquanto que os falantes acima de 49 anos inibem essa variante, com peso relativo de 0,37 . O autor chega à conclusão de que o contexto fonológico precedente é a restrição estrutural mais significativa, sendo favorecida a variante vocalizada quando precedida de vogal baixa ou vogal anterior, como, por exemplo, em "alto", "papel", "anil" 
e "silvo"; de outro lado, o apagamento da lateral /l/ é favorecido quando o contexto precedente apresenta uma vogal posterior $([\mathrm{o}]$ e $[\mathrm{u}])$. Esses resultados, conforme o autor, têm respaldo no Princípio da Saliência Fônica, que preconiza que "[...] o grau de saliência aumenta à medida que passamos da vogal posterior alta $[\mathrm{u}]$ para as vogais não posteriores" (HORA, 2006, p. 39). Tais considerações não excluem a possibilidade de ocorrer o apagamento da lateral em coda silábica precedida por qualquer vogal; no entanto a estigmatização entre pessoas escolarizadas não ocorre quanto ao apagamento precedido pela vogal $[\mathrm{u}]$. Ainda no interior de palavras, o apagamento só ocorre quando precedido de vogal posterior, como, por exemplo, em "pólvora/pó[Ø]vora" e "pulso/pu[Ø]so".

A análise do segmento lateral realizada por Leite, Callou e Moraes (2007) evidencia que as cidades brasileiras de Porto Alegre, São Paulo, Rio de Janeiro, Salvador e Recife apresentam estágios diferentes quanto à implementação da variante vocalizada tanto na fala culta quanto na fala popular. Os autores, considerando a faixa etária dos informantes, notam que esse processo se encontra avançado entre a população mais jovem, mesmo em Porto Alegre, onde a taxa de vocalização gira em torno de $50 \%$ em final de palavra, e que nas demais cidades a taxa chega a $90 \%$ no mesmo contexto.

Brandão (2008), ao analisar o comportamento da variável /1/ em posição de coda na fala fluminense, com dados de informantes analfabetos ou de escolaridade de no máximo até o quarto ano do Ensino Fundamental, conclui que a vocalização, com 87\% de frequência, predomina na comunidade, considerando que o baixo índice de variação entre essa variante e as formas consonantais de / $1 /$ é restrito à faixa etária mais velha.

Comparando os dados de vocalização da fala culta das cidades de Recife (92\%), Salvador (90\%), Rio de Janeiro (88\%), São Paulo (86\%) e Porto Alegre (54\%) na década de 1970, Callou (2009) verifica que o percentual do fenômeno na cidade do Rio de Janeiro não apresenta alterações significativas numa perspectiva de análise em tempo real de curta duração em relação à década de 1990, visto que se trata de uma mudança já efetivada nessa comunidade, e conclui que

a vocalização do /l/ em posição de coda é um processo histórico. Inovador, com certeza, é o avanço do processo no Brasil, que invadiu inclusive áreas consideradas mantenedoras do $/ 1 /$, como a do Rio Grande do Sul. O fenômeno é tão atuante que leva à recuperação do ditongo [ow] $-[\mathrm{kow} \mathrm{a}] \leftarrow$ colcha (que se opõe a coxa) - , ditongo esse quase desaparecido na fala: trouxa $\rightarrow$ [trofa], pouco $\rightarrow$ [poku] (CALLOU, 2009, p. 145). 
Pinho e Margotti (2010) consideram que, "no português do Brasil, a lateral pósvocálica apresenta cinco variantes possíveis, com predomínio da lateral velarizada em certas regiões do Sul, ao passo que a variante vocalizada é a predominante nas outras regiões" (PINHO; MARGOTTI, 2010, p. 67). Em Salvador, por exemplo, segundo os dados do ALiB apresentados por esses autores, das 88 ocorrências da variável /1/, 70 foram da variante vocalizada ([w]) e 14 foram da variante apagamento ([Ø]).

Dentre os grupos de fatores considerados por Oliveira, Costa e Faria (2013), ao estudarem a variação de /1/ na fala de 35 pessoas residentes na zona rural do Nordeste paraense, destacam-se os seguintes ${ }^{5}$ : a) a vogal precedente, em que há especial destaque para a variante $[\varnothing]$ precedida de $[\mathrm{u}]$, com peso relativo de 0,91 , sugerindo que, provavelmente, isso se deve ao reflexo da assimilação que ocorre entre $[\mathrm{u}]$ e $[\mathrm{w}]$; as vogais anteriores e baixa favorecem a vocalização, com pesos de 0,50 e de 0,49 , respectivamente, para [a] e [i], enquanto que, com peso relativo de 0,58 , a vogal posterior [ 0 ] favorece a variante $[\mathrm{h}]$; b) o contexto seguinte, em que, no geral, as consoantes tendem a favorecer a vocalização; c) o modo de articulação da consoante seguinte, em que as fricativas tendem a favorecer o apagamento, enquanto as oclusivas favorecem a aspiração $(0,34)$ e, principalmente, a vocalização $(0,48)$; d) o ponto de articulação da consoante seguinte, em que as consoantes foram classificadas como labiais (labiodentais e bilabiais), alveolares e posteriores (palatalizadas e velares), sendo que o apagamento é favorecido pelas labiais $(0,58)$, a aspiração é favorecida pelas posteriores $(0,68)$ e alveolares $(0,34)$ e a vocalização é favorecida pelas alveolares $(0,48)$.

A partir do exposto, verifica-se que a variável /1/ em coda silábica apresenta um quadro de variação no $\mathrm{PB}$, visto que fatores linguísticos e extralinguísticos atuam para caracterizar cada uma das comunidades de fala já apresentadas.

\section{Procedimentos metodológicos da pesquisa}

Para a composição do corpus desta pesquisa, são consideradas 24 entrevistas com informantes naturais de seis municípios baianos, a saber: Euclides da Cunha, Barra, Jacobina, Seabra, Santo Amaro e Santa Cruz Cabrália. Em cada localidade foram inquiridos

\footnotetext{
5 Os autores fizeram rodadas ternárias, considerando as variantes vocalização, apagamento e aspiração, portanto o ponto considerado neutro passa a ser o peso relativo de 0,33 .
} 
4 informantes, 2 homens e 2 mulheres, distribuídos em duas faixas etárias (faixa 1 - 18 a 30 anos e faixa 2 - 50 a 65 anos), todos alfabetizados, com escolaridade, no máximo, até o Ensino Médio.

Para investigar a realização variável de /1/ em coda silábica no português falado nas comunidades baianas do Projeto ALiB, os dados foram codificados e submetidos a rodadas para análise no Goldvarb X (SANKOFF; TAGLIAMONTE; SMITH, 2005). Trata-se de um programa que analisa estatisticamente os dados, operando com grupos de fatores e com respostas em pesos relativos e significância.

Neste trabalho, consideram-se como variantes de /1/ a "aspiração", considerada uma realização não padrão da consoante /1/ em posição pós-vocálica, como, por exemplo, "ba[h]de" em vez de "balde", com grau social de estigmatização alto; a "vocalização", que é uma realização mais aceita socialmente, como, por exemplo, na pronúncia "a[w]to" da palavra "alto"; e o "apagamento", que é a ausência do fonema na produção da palavra, como, por exemplo, "pessoa[Ø]" em vez de "pessoal”, variante também estigmatizada.

Para o tratamento dos dados, foram definidos os seguintes grupos de fatores linguísticos: 1) tonicidade da sílaba; 2) extensão do vocábulo; 3) vogal precedente; 4) classe morfológica do vocábulo; 5) consoante que inicia a sílaba seguinte ${ }^{6}$; 6) posição no vocábulo; 7) tipo de produção - fala e leitura. Quanto aos grupos de fatores extralinguísticos, foram considerados os seguintes: 1) faixa etária - faixa 1 (18 a 30 anos) e faixa 2 (50 a 65 anos); 2) sexo - masculino e feminino; 3) cidade - Euclides da Cunha, Barra, Jacobina, Seabra, Santo Amaro e Santa Cruz Cabrália.

\section{Análise dos dados e discussão dos resultados}

A análise e as discussões são organizadas em dois pontos centrais: índices percentuais de ocorrências do fenômeno e resultados das rodadas binárias selecionadas pelo Programa Goldvarb X como estatisticamente relevantes para as regras variáveis.

\footnotetext{
${ }^{6}$ Foram excluídos os casos de /l/ em final absoluto seguido de vogal, como em "mal amado".
} 


\section{Distribuição geral dos dados}

O tratamento dos dados de todas as comunidades baianas do Projeto ALiB consideradas nesta pesquisa (Santo Amaro, Santa Cruz Cabrália, Euclides da Cunha, Jacobina, Seabra e Barra) revelou a ocorrência de 4 variantes da lateral pós-vocálica em posição final de sílaba. Além daquelas esperadas (vocalização [w], aspiração [h] e apagamento [Ø]), foi encontrada a realização velarizada [1] de /l/ em posição de coda silábica na fala de um dos informantes da localidade de Seabra, variante que não será tratada nas rodadas binárias. Para melhor visualização da distribuição das variantes da consoante em análise, apresenta-se a Tabela 1, a seguir:

\begin{tabular}{ccc}
\hline Variantes de /1/ & Ocorrências & \% \\
\hline$[$ ł] & 23 & 1 \\
{$[\mathrm{~h}]$} & 56 & 2 \\
{$[\varnothing]$} & 343 & 13 \\
{$[\mathrm{w}]$} & 2153 & 84 \\
Total & $\mathbf{2 5 7 5}$ & $\mathbf{1 0 0}$ \\
\hline
\end{tabular}

Tabela 1: distribuição geral dos dados.

Das 2575 ocorrências, a realização velarizada [ 1$]$ de / $/$ / corresponde a apenas 1\% do total, com 23 dados; a realização aspirada [h] ocorre em apenas $2 \%$ dos dados, com 56 ocorrências; o apagamento [Ø] ocorre em 13\% dos dados, com 343 ocorrências; e a realização vocalizada [w] da consoante chega a atingir 84\%, com 2153 ocorrências.

Verifica-se que a variante vocalizada é a mais empregada nessas comunidades, o que confirma uma das hipóteses da pesquisa: a de que, apesar da alta frequência de seu emprego, a vocalização não constitui uma regra categórica.

Conforme a alta frequência de realização da variante vocalizada (84\%), constata-se o postulado por autores, como, por exemplo, Teixeira (1988), de que essa variante de /1/ em posição final de sílaba é bastante difundida no PB. Essa alta frequência da realização vocalizada pode estar associada ao grau de valoração da variante perante a comunidade de fala. 
Na próxima seção, faz-se a análise das rodadas binárias dos dados obtidas a partir do Goldvarb X, tendo as variantes menos difundidas ([h] e $[\varnothing])^{7}$ entre os falantes das comunidades baianas como valores de aplicação em comparação com a variante vocalizada $[w]$, que é largamente realizada nessas comunidades, conforme as rodadas iniciais mostraram.

\section{Aspiração e vocalização}

Nesta seção, tendo a variante aspirada como valor de aplicação, faz-se a análise dos resultados apresentados pelo Programa Goldvarb X a partir da rodada binária dessa variante com a variante vocalizada. A realização aspirada $[\mathrm{h}]$ de /l/ em posição de coda silábica, conforme já mencionado anteriormente, correspondeu a $2 \%$ do total de dados da pesquisa, com 56 ocorrências, ficando restrita à posição interna de vocábulo. Em posição interna de vocábulo, e em oposição apenas à vocalização, a variante aspirada registrou $5 \%$ do total de ocorrências nesse contexto. Os grupos de fatores selecionados pelo Programa Goldvarb X como estatisticamente relevantes são apresentados no Quadro 1 a seguir, em ordem de importância.

\begin{tabular}{|c|}
\hline Variantes $[\mathbf{h}] \mathbf{e}[\mathbf{w}]$ \\
\hline Consoante que inicia a sílaba seguinte \\
\hline Sexo dos informantes \\
\hline Cidade \\
\hline Vogal precedente \\
\hline
\end{tabular}

Quadro 1: grupo de fatores selecionados na rodada binária ([h] x [w]).

Nota-se que foram selecionados dois grupos de fatores linguísticos, "Consoante que inicia a sílaba seguinte" e "Vogal precedente", e dois extralinguísticos, "Sexo dos informantes" e "Cidade". Com input inicial 0,025, a rodada selecionada apresentou o input final 0,011 e o $\log$ likelihood $-155,067$ bem como a significância 0,000. A seguir, faz-se a análise dos resultados obtidos nas rodadas considerando os fatores linguísticos e extralinguísticos.

\footnotetext{
${ }^{7}$ Como há poucos dados dessas variantes, temos ciência do fato de que as variáveis controladas perderam a ortogonalidade, mas a apresentação dos resultados do modo como se faz aqui se justifica pelo interesse descritivo (não explicativo) dos padrões da variável /1/ em coda, sob análise.
} 


\section{Realização aspirada e fatores linguísticos}

Procedendo à verificação da atuação dos fatores linguísticos para os índices da variante aspirada, faz-se a análise dos resultados apresentados nas tabelas a seguir, considerando a ordem de importância atribuída pelo Programa Goldvarb X às variáveis.

\section{Consoante seguinte}

A primeira variável selecionada foi a "Consoante que inicia a sílaba seguinte" à variável /1/. Os resultados encontrados estão expostos na Tabela 2, a seguir:

\begin{tabular}{crrr}
\hline Consoante que inicia a sílaba seguinte à variável & Oc./Total & $\mathbf{0}$ & $\mathbf{P R}$ \\
\hline /k/ & $21 / 108$ & 19 & $\mathbf{0 , 9 3}$ \\
/g/ & $12 / 108$ & 11 & $\mathbf{0 , 8 4}$ \\
/f/ & $4 / 72$ & 6 & $\mathbf{0 , 6 8}$ \\
/m/ & $9 / 294$ & 3 & $\mathbf{0 , 6 2}$ \\
/ $/$ / & $3 / 119$ & 2 & $\mathbf{0 , 6 1}$ \\
/d/ & $3 / 102$ & 3 & 0,38 \\
/s/ & $2 / 196$ & 1 & 0,26 \\
/t/ & $2 / 277$ & 1 & 0,14 \\
\hline
\end{tabular}

Tabela 2: aspiração e consoante que inicia a sílaba seguinte.

A realização aspirada de /1/ em posição final de sílaba não ocorreu antes das seguintes consoantes e alofones: /n, p, b, 3, z, J, l, r/; [dz, t $]$. Destaque-se que, das 19 consoantes do português, não houve ocorrências da variável dependente antes das consoantes $/ \mathrm{h}, \Lambda, \mathrm{r} /$. As consoantes velares $/ \mathrm{k} / \mathrm{e} / \mathrm{g} /$, com pesos relativos de 0,93 e 0,84 , respectivamente, são as que mais favorecem a realização aspirada. O traço [+ posterior] da consoante também foi apontado por Oliveira, Costa e Faria (2013) como favorecedor da aspiração. Na sequência, verifica-se que as consoantes /f/ (peso relativo de 0,68), /v/ (peso relativo de 0,61 ) e $/ \mathrm{m} /$ (peso relativo de 0,62 ) também favorecem a aspiração de $/ 1 /$. Ao que parece, os pontos de articulação velar e labial atuam no favorecimento da variante em questão. Já as consoantes alveolares inibem a variante aspirada. 


\section{Vogal precedente}

Outra variável que foi considerada estatisticamente relevante para o fenômeno da aspiração de /1/ em posição de coda silábica foi a "Vogal precedente", como apresenta a Tabela 3, a seguir.

\begin{tabular}{crrr}
\hline Vogal precedente & Oc./Total & $\%$ & PR \\
\hline$[\mathrm{u}]$ & $7 / 34$ & 21 & $\mathbf{0 , 9 3}$ \\
{$[\mathrm{o}]$} & $2 / 52$ & 4 & $\mathbf{0 , 8 4}$ \\
{$[\mathrm{a}]$} & $42 / 1442$ & 3 & 0,48 \\
{$[\mathrm{o}]$} & $5 / 323$ & 1 & 0,44 \\
\hline
\end{tabular}

Tabela 3: aspiração e vogal precedente.

Nota-se que não ocorreu realização aspirada da variável /l/ em coda silábica depois de vogal anterior; mas, sim, depois da vogal central [a], com peso relativo de 0,48 , da vogal posterior [0], com peso relativo 0,44, ambas desfavorecedoras do fenômeno, bem como das vogais $[\mathrm{u}]$ e $[\mathrm{o}]$, com pesos relativos de 0,93 e 0,84 , respectivamente, favorecedoras da realização aspirada da variável $/ 1 /$.

Parece que o favorecimento das vogais $[\mathrm{u}]$ e $[\mathrm{o}]$ à variante aspirada possivelmente se dá devido aos traços físico-articulatórios compartilhados por esses elementos: tanto a realização aspirada como as vogais $[\mathrm{u}]$ e $[\mathrm{o}]$ são posteriores bem como compartilham o mesmo ponto de articulação, situado na parte posterior da cavidade bucal, no véu palatino. Assinala-se ainda que, durante a produção da variante aspirada, a língua enquanto articulador se posiciona semelhantemente ao modo assumido quando da produção dessas duas vogais.

\section{Realização aspirada e fatores extralinguísticos}

Nesta seção, faz-se a análise dos fatores extralinguísticos a partir dos resultados obtidos na rodada binária entre a variante aspirada e a variante vocalizada. Foram selecionados como estatisticamente relevantes para a realização do fenômeno da aspiração de /1/ os grupos de fatores "Sexo dos informantes" e "Cidade". 


\section{Sexo dos informantes}

Quanto ao "Sexo dos informantes", a Tabela 4 apresenta os resultados encontrados.

\begin{tabular}{crrr}
\hline Sexo dos informantes & Oc./Total & \% & PR \\
\hline Homem & $45 / 1156$ & 4 & $\mathbf{0 , 6 9}$ \\
Mulher & $11 / 1053$ & 1 & 0,29 \\
\hline
\end{tabular}

Tabela 4: aspiração e sexo dos informantes.

Os homens falantes das comunidades baianas sob análise são os maiores responsáveis pela realização aspirada de /1/ em posição final de sílaba, com peso relativo de 0,69, enquanto as mulheres, com 0,29 de peso relativo, inibem o emprego dessa variante. Trata-se de uma variante não padrão do PB e estigmatizada socialmente, o que provavelmente explique a baixíssima adesão das mulheres à realização aspirada da variável $/ 1 /$.

\section{Cidade}

Na Tabela 5, a seguir, exibem-se os resultados para a variável "Cidade".

\begin{tabular}{crrr}
\hline Cidade & Oc./Total & \% & PR \\
\hline Seabra & $22 / 281$ & 8 & $\mathbf{0 , 8 8}$ \\
Jacobina & $9 / 216$ & 4 & $\mathbf{0 , 7 3}$ \\
Santa Cruz Cabrália & $8 / 430$ & 2 & 0,48 \\
Euclides da Cunha & $9 / 611$ & 1 & 0,40 \\
Barra & $6 / 350$ & 2 & 0,37 \\
Santo Amaro & $2 / 321$ & 1 & 0,27 \\
\hline
\end{tabular}

Tabela 5: aspiração e cidade.

Das seis localidades investigadas, apenas a cidade de Seabra, com peso relativo de 0,88 , e a cidade de Jacobina, com peso relativo de 0,73 , são favorecedoras da realização aspirada de /1/ em posição final de sílaba. As demais cidades (Santa Cruz Cabrália, com peso relativo de 0,48; Euclides da Cunha, com peso relativo de 0,40; Barra, com peso relativo de 0,37; e Santo Amaro, com relativo de 0,27) a inibem. 


\section{Apagamento e vocalização}

Nesta seção, faz-se a análise dos resultados apresentados pelo Programa Goldvarb $\mathrm{X}$ a partir da rodada binária entre as variantes apagamento $[\varnothing]$ e vocalização $[\mathrm{w}]$, tomando a primeira como regra de aplicação. $O$ apagamento da variável /l/ em posição final de sílaba somou 343 registros do total de dados, representando 13\% dos dados analisados.

Considerando os contextos de ocorrências de /1/ em posição de coda silábica, a variável registrou 1285 ocorrências em posição interna de vocábulo, das quais 197 foram de apagamento, correspondendo ao índice de 15\%, enquanto que, nas posições final interna e final absoluta, juntamente, a variável /1/ marcou presença 1290 vezes, das quais 146 foram de apagamento, correspondendo ao índice de 11\%.

O apagamento da variável / $/$ / em posição de coda silábica foi registrado nos três contextos de vocábulo - interno, final interno e final absoluto -, sendo que sua menor frequência de ocorrência se deu em posição final interna de vocábulo, em que, das 540 realizações de /1/ nesse contexto, apenas 45 foram de apagamento, correspondendo a 8\% do total nessa posição. Destaque-se que a "posição da variável no vocábulo" não foi selecionada como estatisticamente relevante para o apagamento da variável /1/ em coda silábica durante a rodada binária entre essa variante e a vocalização.

No Quadro 2 são apresentados os grupos de fatores considerados estatisticamente relevantes para o apagamento da variável dependente em ordem de importância.

\begin{tabular}{|c|}
\hline Variantes [Ø] e [w] \\
\hline Vogal precedente \\
\hline Consoante que inicia a sílaba seguinte \\
\hline Tonicidade da sílaba \\
\hline Cidade \\
\hline Extensão do vocábulo \\
\hline Sexo dos informantes \\
\hline Classe morfológica do vocábulo \\
\hline Faixa etária dos informantes \\
\hline
\end{tabular}

Quadro 2: grupo de fatores selecionados na rodada binária ([Ø] x [w]). 
O input inicial da rodada foi 0,137 , enquanto que o input final foi 0,029 . O $\log$ likelihood foi -547,981 e o nível de significância foi 0,005. Inicialmente, são apresentados os resultados das variáveis linguísticas; posteriormente, os das variáveis extralinguísticas.

\section{Apagamento e fatores linguísticos}

\section{Vogal precedente}

No que tange à variável "Vogal precedente", a Tabela 6, a seguir, mostra os resultados estatísticos para o apagamento do /1/ em posição final de sílaba.

\begin{tabular}{crrr}
\hline Vogal precedente & Oc./Total & $\%$ & $\mathbf{P R}$ \\
\hline$[\mathbf{u}]$ & $112 / 139$ & 81 & $\mathbf{0 , 9 9}$ \\
{$[\mathbf{o}]$} & $41 / 91$ & 45 & $\mathbf{0 , 9 4}$ \\
{$[\mathbf{D}]$} & $78 / 396$ & 20 & $\mathbf{0 , 8 9}$ \\
{$[\mathbf{i}]$} & $36 / 210$ & 17 & $\mathbf{0 , 6 0}$ \\
{$[\boldsymbol{\varepsilon}]$} & $7 / 190$ & 4 & 0,32 \\
{$[\mathbf{a}]$} & $69 / 1469$ & 5 & 0,22 \\
\hline
\end{tabular}

Tabela 6: apagamento e vogal precedente.

Das sete vogais orais do PB, somente após a vogal [e] não se registrou o fenômeno apagamento, uma vez que o único caso de registro de ocorrência da consoante $/ 1 / \mathrm{em}$ posição final de sílaba antecedida pela vogal anterior média alta resultou na vocalização da variável - a palavra "feltro", pronunciada ['fewtro]. A probabilidade de que ocorra o apagamento de /1/ em coda após as vogais posteriores $[0],[\mathrm{o}] \mathrm{e}$, principalmente, [u] é bastante alta, com pesos relativos de 0,89, 0,94 e 0,99, respectivamente, assim como após a vogal anterior alta [i]. Parece que os traços $[+$ posterior $]$ e $[+$ alta $]$ atuam para a alta frequência do apagamento, visto que as vogais com traços [- posterior] e [- alta] são desfavorecedoras, como ocorre com a vogal [a], com peso relativo de 0,22 , e a vogal $[\varepsilon]$, com peso relativo de 0,32. Esses resultados corroboram os apresentados por Teixeira (1988), sobre os dados de Monte Santo, que verificou o índice mais alto de favorecimento do apagamento diante de $[\mathrm{u}]$, com diminuição desse índice paulatinamente diante [0], [i] e $[\varepsilon]$, até chegar a zero diante de [a]. Destaque-se que essa autora considerou as vogais [o] e [0] como um único fator: [ొ]. 
Cumpre registrar os casos em que houve tanto vocalização como apagamento em vocábulos de mesmo contexto linguístico, como, por exemplo, o substantivo "alface" e o pronome "qualquer", em que a vogal antecedente à variável é [a].

Em Jacobina, o apagamento de /1/ em coda silábica no vocábulo "alface" ocorreu todas as vezes em que houve o alteamento posterior da vogal central baixa [a] que antecede a variável para [0]: “o[Ø]face”. Verificou-se ainda que as mulheres jacobinenses somente apagaram o / / nos contextos em que houve o referido alteamento posterior da vogal antecedente, enquanto os homens realizaram o apagamento tanto diante da vogal [a] (“a[Ø]face”) quanto diante do alteamento posterior dessa vogal para [॰].

Para o vocábulo "alface", todos os homens santo-amarenses realizaram apagamento tanto diante da vogal antecedente [a] ("a[Ø]face") quanto diante de seu alteamento posterior para [0] (“o[Ø]face”), enquanto que as mulheres preservaram a vocalização diante de [a] ("a[w]face"), sem registros de alteamento posterior da vogal. Isso demostra a resistência desse contexto à variante apagamento, ou seja, se a vogal precedente à variável dependente for [a], significa que haverá maior resistência ao apagamento de /1/ em coda silábica, com a realização da variante vocalizada.

A realização variável do /1/ em posição de coda silábica diante do alteamento posterior da vogal que a antecede também foi registrada na localidade de Santa Cruz Cabrália. Neste caso, no vocábulo "alface", os homens santa-cruzenses tanto apagaram quanto vocalizaram a variável dependente diante da vogal antecedente [a] ("a[Ø]face", "a[w]face"), mas apenas apagaram o / / diante do alteamento posterior da vogal /a/antecedente para [o], a exemplo do vocábulo "qualquer", realizado "quo[Ø]quer", tendo sido registrado também "qua[Ø]quer". Ainda no que tange ao vocábulo "alface", as mulheres dessa localidade produziram apenas a realização vocalizada diante da vogal antecedente $[\mathrm{a}]$ ("a $\mathrm{a} \mathrm{w}]$ face”), sem ocorrências de alteamento vocálico; entretanto, no vocábulo "álcool”, em que há a dupla presença da variável /1/, com contextos antecedentes diferentes, registraram-se na fala de uma das informantes sua realização vocalizada diante da vogal central [a] e seu apagamento diante da vogal posterior [o]: "a[w]coo[Ø]".

Assim, as ocorrências descritas anteriormente podem comprovar o favorecimento do apagamento da lateral pós-vocálica /1/ em coda silábica pelas vogais posteriores. 


\section{Consoante seguinte}

A Tabela 7, a seguir, sistematiza os resultados da influência do grupo de fatores "Consoante que inicia a sílaba seguinte" sobre a variante apagamento.

\begin{tabular}{crrr}
\hline Consoante que inicia a sílaba seguinte & Oc./Total & $\mathbf{\%}$ & $\mathbf{P R}$ \\
\hline /f/ & $23 / 91$ & 25 & $\mathbf{0 , 9 2}$ \\
/v/ & $57 / 173$ & 33 & $\mathbf{0 , 9 1}$ \\
/ $/$ & $2 / 37$ & 5 & $\mathbf{0 , 8 7}$ \\
/n/ & $17 / 116$ & 15 & $\mathbf{0 , 7 8}$ \\
/ $/$ & $13 / 100$ & 13 & $\mathbf{0 , 7 4}$ \\
/s/ & $36 / 230$ & 16 & $\mathbf{0 , 6 5}$ \\
/d/ $\rightarrow$ [d3] & $3 / 76$ & 4 & $\mathbf{0 , 6 3}$ \\
/b/ & $2 / 8$ & 25 & $\mathbf{0 , 5 9}$ \\
/t/ $\rightarrow$ [t]] & $29 / 36$ & 81 & $\mathbf{0 , 5 7}$ \\
/g/ & $9 / 105$ & 9 & $\mathbf{0 , 5 3}$ \\
/p/ & $16 / 56$ & 29 & $\mathbf{0 , 5 1}$ \\
/m/ & $6 / 291$ & 2 & 0,21 \\
/t/ & $21 / 296$ & 7 & 0,20 \\
/d/ & $8 / 107$ & 7 & 0,02 \\
\hline
\end{tabular}

Tabela 7: apagamento e consoante que inicia a sílaba seguinte.

As consoantes oclusivas mais anteriores desfavorecem o apagamento de /l/ em posição de coda silábica, como ocorreu com as consoantes $/ \mathrm{m} / \mathrm{t} / \mathrm{t} / \mathrm{e} / \mathrm{d} /$, com pesos relativos correspondentes de 0,21, 0,20 e 0,02, nesta ordem, considerando que a consoante /b/ registrou poucos dados (8) em comparação com aquelas três e a consoante /p/ apresentou peso relativo de 0,51 , muito próximo ao ponto neutro. $\mathrm{O}$ apagamento parece ser motivado pelas fricativas /f/ (com pesos relativo de 0,92), /v/ (com peso relativo de $0,91), / \mathrm{J} /$ (com peso relativo de 0,87 ) e /s/ (com peso relativo de 0,65); pelas africadas [d3] (com peso relativo de 0,63) e [t]] (com peso relativo de 0,57); bem como pela nasal alveolar /n/ (com peso relativo de 0,78) e pelas oclusivas posteriores / $/$ / (com peso relativo de $0,74)$ e $/ \mathrm{g} /$ (com peso relativo de 0,53 ). 


\section{Tonicidade da sílaba}

A Tabela 8 apresenta os resultados levando em consideração os efeitos do grupo de fatores "Tonicidade da sílaba" na aplicação da variante apagamento.

\begin{tabular}{crrr}
\hline Tonicidade da sílaba & Oc./Total & $\%$ & PR \\
\hline Átona & $135 / 879$ & 15 & $\mathbf{0 , 7 6}$ \\
Tônica & $208 / 1617$ & 13 & 0,34 \\
\hline
\end{tabular}

Tabela 8: apagamento e tonicidade da sílaba.

O apagamento da consoante /l/ em posição final de sílaba é favorecido pela sílaba átona, com peso relativo de 0,76 , enquanto que, em posição tônica, há o desfavorecimento dessa variante, com peso relativo de 0,34. Oliveira, Costa e Faria (2013) também observaram em sua análise o favorecimento do apagamento da variável /1/ em posição de coda silábica em sílabas átonas.

\section{Extensão do vocábulo}

A Tabela 9 sintetiza os resultados considerando a influência do grupo de fatores "Extensão do vocábulo" na aplicação do apagamento da variável dependente analisada.

\begin{tabular}{crrr}
\hline Extensão do vocábulo & Oc./Total & \% & PR \\
\hline Dissilábico & $138 / 964$ & & $\mathbf{0 , 6 3}$ \\
Três ou mais sílabas & $176 / 1140$ & 15 & 0,49 \\
Monossilábico & $29 / 392$ & 7 & 0,21 \\
\hline
\end{tabular}

Tabela 9: apagamento e extensão do vocábulo.

Os vocábulos dissilábicos se mostraram favorecedores da aplicação dessa variante, com peso relativo de 0,63. Já os vocábulos monossilábicos e aqueles com três sílabas ou mais inibiram o apagamento de /1/ em coda silábica. 


\section{Classe morfológica}

Outro grupo de fatores linguísticos selecionado pelo Goldvarb X como relevante na aplicação do apagamento foi a "Classe morfológica do vocábulo", conforme a seguir.

\begin{tabular}{crrr}
\hline Classe morfológica do vocábulo & Oc./Total & \% & PR \\
\hline Nomes (sub. e adj.) & $310 / 2116$ & 15 & $\mathbf{0 , 5 2}$ \\
Pronomes & $8 / 99$ & 8 & $\mathbf{0 , 5 1}$ \\
Advérbios & $11 / 136$ & 8 & 0,50 \\
Verbos & $14 / 145$ & 10 & 0,16 \\
\hline
\end{tabular}

Tabela 10: apagamento e classe morfológica do vocábulo.

Verifica-se que a classe morfológica dos nomes (substantivos e adjetivos), com peso relativo de 0,52 , dos pronomes, com peso relativo de 0,51 , e dos advérbios, com peso relativo de 0,50 , apresentaram resultados em torno do ponto neutro. Já os verbos inibem o apagamento da variável, com peso relativo de 0,16.

\section{Apagamento e fatores extralinguísticos}

Nesta seção, discutem-se os resultados obtidos na rodada binária entre o apagamento e a vocalização do /1/ em coda silábica para as variáveis extralinguísticas consideradas estatisticamente relevantes para o apagamento. Foram selecionados pelo Programa Goldvarb X os grupos de fatores "Cidade", "Sexo" e "Faixa etária".

\section{Cidade}

Os resultados para a variável “Cidade” são apresentados na Tabela 11, seguinte.

\begin{tabular}{crcc}
\hline Cidade & Oc./Total & $\%$ & PR \\
\hline Jacobina & $55 / 262$ & 21 & $\mathbf{0 , 7 0}$ \\
Santa Cruz Cabrália & $83 / 505$ & 16 & $\mathbf{0 , 6 4}$ \\
Santo Amaro & $51 / 370$ & 14 & $\mathbf{0 , 5 6}$ \\
Seabra & $48 / 307$ & 16 & $\mathbf{0 , 5 6}$ \\
Barra & $45 / 389$ & 12 & 0,37
\end{tabular}




\section{$\begin{array}{llll}\text { Euclides da Cunha } & 61 / 663 & 9 & 0,31\end{array}$}

Tabela 11: apagamento e cidade.

Os resultados demonstram que a cidade de Jacobina, com peso relativo de 0,70, é a principal favorecedora da aplicação do apagamento da consoante /1/ em coda silábica. Em segundo lugar, está a cidade de Santa Cruz Cabrália, com peso relativo de 0,64. As cidades de Santo Amaro e de Seabra também favorecem essa variante, ambas com pesos relativos de 0,56. As cidades de Barra, com peso relativo de 0,37, e de Euclides da Cunha, com peso relativo de 0,31, inibem a regra de apagamento. Esse quadro variável revela que as localidades baianas selecionadas apresentam estágios diferentes da realização variável de /1/ em coda silábica.

\section{Sexo}

A variável "Sexo" exibiu os resultados expostos na Tabela 12, a seguir.

\begin{tabular}{cccc}
\hline Sexo dos informantes & Oc./Total & \% & PR \\
\hline Homem & $208 / 1319$ & 16 & $\mathbf{0 , 5 6}$ \\
Mulher & $135 / 1177$ & 11 & 0,42 \\
\hline
\end{tabular}

Tabela 12: apagamento e sexo dos informantes.

Os resultados revelam que os homens das localidades baianas tendem a favorecer a aplicação do apagamento, com peso relativo de 0,56 , enquanto que as mulheres inibem essa variante, com peso relativo de 0,42 .

\section{Faixa etária}

Quanto à variável "Faixa etária", a tabela a seguir apresenta os resultados encontrados na pesquisa. 


\begin{tabular}{crrr}
\hline Faixa etária dos informantes & Oc./Total & $\%$ & PR \\
\hline Faixa 2 (50 a $\mathbf{6 5}$ anos) & $222 / 1431$ & 15 & $\mathbf{0 , 5 5}$ \\
Faixa 1 (18 a 30 anos) & $121 / 1065$ & 11 & 0,42 \\
\hline
\end{tabular}

Tabela 13: apagamento e faixa etária dos informantes.

É possível perceber o desfavorecimento do apagamento pela faixa etária mais jovem, com peso relativo de 0,42 , enquanto a faixa etária mais velha é favorecedora dessa variante. Esse quadro sugere uma tendência à mudança nas localidades baianas examinadas em direção à implementação da variante vocalizada e a uma diminuição gradativa do apagamento da variável, restringindo esta última a certos contextos linguísticos, menos estigmatizados, como, por exemplo, antecedida das vogais [u] e [o], em palavras como "agricu[Ø]tura”, “cu[Ø]tura”, “desenvo[Ø]vimento”, “álcoo[Ø]” etc.

\section{Conclusões}

A pesquisa teve como objetivo investigar a realização variável da lateral pósvocálica /1/ em posição de coda silábica em comunidades baianas do Projeto ALiB, considerando tanto fatores linguísticos como extralinguísticos imbricados no fenômeno. Essa consoante apresentou diferentes realizações: a vocalizada ([w]), o apagamento ([Ø]) e a aspirada $([\mathrm{h}])$.

A análise da realização variável da lateral pós-vocálica /1/ em posição de coda silábica demonstrou que a variante vocalizada $[\mathrm{w}]$ encontra-se amplamente difundida entre os falantes das cidades baianas selecionadas, a saber, Santo Amaro, Santa Cruz Cabrália, Euclides da Cunha, Seabra, Barra e Jacobina, apresentando as maiores frequências de uso em todas as localidades.

A maior frequência de apagamento da variável foi registrada na localidade de Jacobina, que chegou a atingir o índice de $20 \%$ do total de ocorrências. O apagamento, no que tange aos fatores linguísticos, foi favorecido pelo traço de posterioridade da vogal antecedente, como $[\mathrm{u}],[\mathrm{o}]$ e $[\mathrm{\jmath}]$, e pelas consoantes fricativas, principalmente, bem como pelas sílabas átonas e pelos vocábulos dissilábicos. 
Os fatores extralinguísticos se mostraram importantes para a frequência de uso das variantes apagamento e aspiração nas localidades baianas selecionadas, sendo as cidades de Jacobina, Santa Cruz Cabrália, Santo Amaro e Seabra, nesta ordem, favorecedoras do apagamento e as cidades de Barra e Euclides da Cunha desfavorecedoras. Os informantes do sexo masculino favorecem o apagamento de /1/ em posição de coda silábica, com peso relativo de 0,56 , enquanto que os do sexo feminino o inibem, com peso relativo de 0,42 . A variável "Faixa etária" revelou que os mais jovens têm abandonado a variante apagamento em favor da variante vocalizada, visto que, com peso relativo de 0,42 , essa faixa etária é desfavorecedora do apagamento, enquanto que a faixa etária mais velha, com peso relativo de 0,55 , é favorecedora dessa variante, fato que leva a entrever uma tendência à mudança, considerado o tempo aparente.

Visto o quadro variável apresentado em cada uma das cidades consideradas, nota-se que a implementação da variante vocalizada da lateral pós-vocálica em posição de coda silábica apresenta, entre as localidades, discretas diferenças em seus estágios.

A variante aspirada ficou restrita à posição interna de vocábulo. Ao que parece, os fatores linguísticos favorecedores dessa variante são, principalmente, os traços de posterioridade das consoantes velares $/ \mathrm{k} / \mathrm{e} / \mathrm{g} /$ e das vogais $[\mathrm{u}]$ e $[\mathrm{o}]$. Quanto aos fatores extralinguísticos favorecedores dessa variante, os homens, com 0,69 de peso relativo, aspiram mais do que as mulheres, com 0,29 de peso relativo. E as cidades de Seabra, com peso relativo de 0,88 , e Jacobina, com peso relativo de 0,73 , também favorecem essa variante.

Desse modo, as hipóteses levantadas são confirmadas: o /1/ em posição final de sílaba é variável na fala das comunidades investigadas, com a variante vocalizada [w] já bastante disseminada no interior baiano, mas não de maneira categórica; esse fenômeno é condicionado por fatores linguísticos e sociais; a variação da lateral pós-vocálica $/ 1 / \mathrm{em}$ posição de coda silábica aponta para uma mudança em progresso no interior baiano na direção da variante vocalizada [w], em detrimento do apagamento. 


\section{Referências}

BRANDÃO, S. F. A geografia linguística no Brasil. São Paulo: Ática, 1991.

. Variação em coda silábica na fala popular fluminense. Revista da ABRALIN v. 7, no 1, Jan./Jun. 2008, p. 177-189.

CALLOU, D. Um perfil da fala carioca. In: RIBEIRO, S. S. C.; COSTA, S. B. B.; CARDOSO, S. A. M. (Org.). Dos sons à fala: nas trilhas da língua portuguesa. Salvador: Edufba, 2009, p. 131-152.

COMITÊ NACIONAL DO PROJETO ALiB. Atlas linguístico do Brasil: questionários. Londrina: UEL, 1998.

HORA, D. Variação da lateral /1/: correlação entre restrições sociais e estruturais. Scripta, Belo Horizonte, v. 9, $\mathrm{n}^{\circ} .18,1^{\circ}$ semestre 2006, p. 29-44.

LABOV, W. Padrões sociolinguísticos. Trad. Marcos Bagno. São Paulo: Parábola, 2008 [1972].

LEITE, Y.; CALLOU, D.; MORAES, J. O /1/ em posição de coda silábica: confrontando variedades. ENCONTRO NACIONAL DA ASSOCIAÇÃO PORTUGUESA DE LINGUÍSTICA, 2007, 22. Lisboa. Atas... Lisboa: APL, 2007, p. 423-430.

OLIVEIRA, M.; COSTA, C.; FARIA, M. A. A lateral pós-vocálica no Nordeste paraense: uma descrição geo-sociolinguística. In: AGUILERA, V. A. (Org.). A geolinguística no Brasil: trilhas seguidas, caminhos a percorrer. Londrina: Eduel, 2013, p. 406-429.

PINHO, A. J.; MARGOTTI, F. W. A variação da lateral pós-vocálica /L/ no português brasileiro. Working Papers em Linguística, Florianópolis, nº. 2, 2010, p. 67-88.

SANKOFF, D.; TAGLIAMONTE, S.; SMITH, E. GoldVarb X - a multivariate analysis application. Toronto: Department of Linguistics; Ottawa: Department of Mathematics, 2005. Disponível em: <http://individual.utoronto.ca/tagliamonte/

Goldvarb/GV_index.htm\#ref>. Acesso em: 20 de Mar. 2016.

TEIXEIRA, E. S. P. Variação e mudança linguísticas na região de Monte Santo. Dissertação (Mestrado em Letras). Salvador: Universidade Federal da Bahia, 1988. 


\begin{abstract}
Based on the theoretical and methodological assumptions of Labovian sociolinguistics and multidimensional geolinguistics, this article aims to investigate the variable realization of the post-vocalic lateral / $/ /$ in coda position in Bahia communities of the Linguistic Atlas of Brazil Project (ALiB Project). For this purpose, we analyze a corpus with 24 interviews with natural informants from the following locations, members of the ALiB Project network: Euclides da Cunba, Barra, Jacobina, Seabra, Santo Amaro and Santa Cruz Cabrália. The results point to a tendency to change, in which the erasing of the dependent variable has been abandoned by the younger informants in favor of the vocalized variant, so that the implementation of the vocalization presents different stages in each of the selected localities.
\end{abstract}

Keywords: /l/ in syllable coda. Sociolinguistics. Geolinguistics. ALiB Project

Recebido em: 18/02/2018.

Aceito em: 11/06/2018. 